\title{
The Great Gap in Basic Education
}

\author{
Paul A. Wagner \\ Coordinating Chair, Educational Statistics and Psychology, College of Education, University of Houston, Clear Lake, USA \\ Email:wagner@uhcl.edu
}

How to cite this paper: Wagner, P. A. (2022). The Great Gap in Basic Education. Creative Education, 13, 128-134. https://doi.org/10.4236/ce.2022.131009

Received: November 20, 2021

Accepted: January 16, 2022

Published: January 19, 2022

Copyright (c) 2022 by author(s) and Scientific Research Publishing Inc. This work is licensed under the Creative Commons Attribution International License (CC BY 4.0).

http://creativecommons.org/licenses/by/4.0/

\begin{abstract}
Despite claims that education is not addressing basic education and so-called life skills, such claims must be weighed against what various constituencies count as basic and more so, life-skills. Most decidedly the inclusion of instruction first in natural frequency evaluation and then in Bayesian reasoning is critical as Gigerenzer et al. (2015) have shown. Certainly, there is a cost to the inclusion of any material especially as proposed herein. But the cost when it leads to more effective evaluations of truth across the curriculum is worth it considering the "Law of Figuring it Out, LFTO as proposed by Wagner et al. (2018). This article explains why Gigerenzer's focus on statistical reasoning across the curriculum advances the concept behind a generalized commitment to evaluative reasoning as is proposed in the LFTO. The sketch to follow proposes that the fourth " $r$ " reasoning includes instruction in statistical thinking to make all students more mindful of LFTO practices when seeking understanding rather than mere recollection skills. Modification of material in mathematics, social studies, science and, where it exists, philosophy for children, can emphasize the importance of justification as indispensable to genuine insight.
\end{abstract}

\section{Keywords}

Statistics, Evaluation, Critical Thinking, Pandemic, Probability, Law of Figuring Things Out

\section{Introduction}

News media often suggest that schools are not teaching practical skills. Depending on the story the practical skills named include balancing a check book, maintenance of proper hygiene, finding public and social services, avoiding pollution, how best to re-cycle materials and even how to change diapers. These are important things to learn. So too it might be important to learn not to bet on the draw for completing an inside straight in poker. There are many practical and 
prudential matters students can benefit from learning, but is mere utility sufficient argument for including them in the school curriculum?

The Basic Gap refers not to an overview of all education but rather a gap in one of the areas that so often is referred to as "a basic", namely " $r$ ", reasoning and critical thinking. Taxonomic lists of reasoning qualities are often. Too often, these lists fail to be comprehensive. More problematic, they typically overlook standard approximation assessments such as rudimentary training in Bayesian reasoning and identification of what Gigerenzer (2014: pp. 210-216) describes as natural frequencies. Finally, standardized statistical interrogatories for evaluation of approximation claims are seldom addressed outside courses in later grades dedicated specifically to statistical training. This must change. As psychologist Pinker (2021: p. 314) explained earlier this year in his monumental book Rationality, "Educational institutions, from elementary schools to universities could make statistical and critical thinking a greater part of their curriculum... rationality should be the fourth r...". Without a robust attention to the statistical foundation of the fourth " $r$ " the gap in basic education will never be closed.

\section{Thumbnail Exemplar of the Problem}

How often students play poker should be a consideration if contemplating instruction in poker strategy. So too rationality and the other basics, should be considered for their general utility and broad application to life's challenges most students are likely to encounter. Also relevant is whether substantive inclusion of new material can be accomplished without disrupting the curriculum as it currently stands. Finally, curricular additions must be evaluated in reference to psychological principles of learning and the costs to the public for implementation (Wagner \& Dede, 1983).

An obvious standard for first order evaluation of what should go into the curriculum is: Establish the extent to which schools are the most uniquely effective strategy for students to learn new basics and the value to the public of such learned achievements.

People learn not just in school but in environmental prompts of all sorts. Schools are not the only place learning does or, should take place. Schools are first and foremost, places where instruction received depends on professional expertise of instructors. Many matters of practical and prudential value can be taught at home and in local communities. There is a reason schools specialize in teaching the four " $r$ 's": reading, writing, arithmetic, and reasoning. And the more in depth such instruction becomes the less they can be expected to be taught at home. Parents have careers and are managing a home life besides. Few parents have time to study increasingly dense subject matter or principles of educational psychology to instruct their offspring appropriately.

Other skills of likely utility can be taught at school but only at the expense of crowding out the four "r's" which nearly all agree are indispensable learnings. 
For example, schools could teach students how to change a tire, not to answer a doorbell to a stranger, or change a fuse but cannot such things be readily taught by most non-specialist parents?

\section{Be on the Lookout for Problems}

Just because something can be taught in the schools does not mean they should be taught there rather than at home or elsewhere. Matters that are taught in the schools beyond the four " $r$ 's" are closely derivative from the skills, attitudes, dispositions, and resources integral to the four "r's". Education is first and foremost an institution for student-building (Wagner \& Fair, 2020: pp. 127-129) and, subsequently for bringing students into full and lifetime participation in The Great Conversation of Humankind seeking truth and well-being writ large for all (Wagner \& Simpson, 2009: pp. 114-115).

Besides integral to the four " $r$ 's", inclusion in the public-school curriculum should also reflect that the learning involved requires formal instructional planning involving rubrics, grading, lesson plans, assessment and evaluation and other things highly-trained specialists bring to managing the student-building task.

All the learnings mentioned above have potential advantage to those who can execute them in context. But, only learning the "four r's" and derivative material has proven utility extending across a vast array of application basics for nearly all student-building challenges leading to competent performance as citizens of the republic, parents, career specialists and so on.

Those who want to play poker can learn and improve strategies for doing so without ever relying on public school education. These things could be taught. But it is unlikely that formal education is required to learn such fundamental rules and inferencing patterns (unless perhaps in advanced post-secondary instruction in applied math or economic game theory). Poker-playing like so many other things is aptly taught through learning resources within cultural immersion and requiring no formal schooling. Indeed, as psychologist Steven Pinker notes the Sans, a people of so-called undeveloped civilization, are sensitive to Bayesian statistical reasoning without the advantage of formal schooling. Nonetheless, as context becomes more complex, the advantages of formal training in statistical reasoning advances pragmatic skills in what was already recognized intuitively as advantageous thinking protocols (Pinker, 2021: pp. 166-169).

Families, hospitals, and social services do a superb job of teaching young parents how to change diapers. In short, many things some want placed in the public-school curriculum are addressed sufficiently by other social resources. Sacrificing the resources of formal education for these new tasks in "cultural basics" is costly in terms of student intellectual development. Merely noting needs and benefits does not establish the wisdom of introducing new material that sacrifice the four "r's" and derivative subject material. New material cannot be added endlessly. 


\section{Problems in the Past Are Still with Us}

The content of public education is bounded. What goes into the curriculum must justify what should be removed to accommodate the new. The range of curricular inclusion cannot be expanded indefinitely nudging all students into a one size fits all especially ignoring the most basic of the basics in the process (Jackson, 2011).

Admittedly there are life skills that not adequately addressed by the cultural surrounds of many students. But that alone does not justify downloading all social and learning challenges onto the public school, curricular platform. There is at least one of the four "r's" that seems especially accommodating to much of the "new basics" many reformers are crying out for. And developing that " $r$ " will address indirectly many of the other learning needs reformers advocate. That " $r$ " is the skill of reasoning. When student-building, the most central of all basics is what Wagner et al. (2018: pp. 50-54) call the LAW OF FIGURING THINGS OUT-LFTO.

Students who reason best in the widest of contexts are in the best position to push past brute wants and uninformed opinions to face conditions of uncertainty. In addition, not only are those who value the LFTO better at managing impending challenges they are also better able to grapple with the challenges of advancing their understanding within the curriculum of the other three "r's (Lipman, 2003). Students who embrace the LFTO recognize that in both truth-seeking and truth securing efforts the goal is to approximate representations of reality free from evident error.

The lament that employers, parents, scholars, and senior educators find most agitating is the absence of critical thinking. These folks believe that the emphasis on standardized tests has pushed aside development of student critical thinking skills, attitudes, and dispositions (Poundstone, 2021: pp. 244-246; Koretz, 2008).

So much has been written about the need for greater attention to critical thinking that it would be redundant to delve further into the matter at this point. One element of the LFTO that gets the least attention and perhaps deserves the most, is instruction in statistical thinking. As psychologist and director of the Max Plank Institute, Behavioral Science Unit, Gerd Gigerenzer explains elements of statistical thinking, a form of inductive logic can begin as early as the elementary grades. Gigerenzer also advocates that in all education beyond the elementary grades further practice in statistical evaluation of truth claims and planning recommendations should be ubiquitous (Gigerenzer, 2014). There are few areas from science, math, social studies, reading, and personal planning and civic participation that would not be improved by greater sophistication throughout the public at every age. Yet this fundamental element of what Wagner and associates describe as the LFTO gets little attention until high school math courses or upper division college courses.

\section{Statistical Thinking Part of the LFTO}

Statistical thinking is one of those things that cannot be taught reliably at home 
or absorbed through immersion in culture and requires specialists and structured rubrics for curricular scaffolding. Salespeople, journalists, and many others use statistical generalizations to bolster a claim. Yet only because of specialized training can people learn to effectively evaluate such claims. When people have no understanding of statistical evaluation, they are at the mercy of the purveyor of information to be truthful and infallibly accurate in how the data summarized was managed. This leads to a public vulnerable to the shenanigans of society's cleverest manipulators of information. In short by, developing skills of statistical evaluation people are freed from much predation and better skilled at directing their own and their community's lives more pragmatically consistent with shared purpose.

Statistical thinking requires formal instruction (Wagner, 2021). The challenges of utilizing statistical thinking to make informed, life-sustaining judgments has recently been highlighted by the deluge of pandemic data (Gottlieb, 2021; Hotez, 2021). Moreover, unexplained statistical conclusions are too often used as a tool by those who wish to persuade rather than inform (Spiegelhalter, 2019). Understanding statistical evaluation is a life skill of critical evaluation (Cairo, 2019). This makes statistical understanding an immediate and practical for all engaged in the practice of student-building for responsible, adult decision-making (Wagner, Johnson, Fair, \& Fasko, 2018).

All students need to make statistical judgements throughout their lives. The standard of student need is unambiguously transparent (Cairo, 2019: pp. 18-19). There is little opportunity to learn about statistical thinking outside of formal schooling. Statistical evaluation can and should be taught to students continuously from first grade onward. Gigerenzer (2014: pp. 260-261) explains how natural, probabilistic reasoning in the earliest elementary grades can accustom students to naturalistic, statistical reasoning later. Gigerenzer subsequently explains how, with such learned anticipations in hand, more sophisticated understanding of risk evaluation and planning can be augmented by formal training in statistical concepts and Bayesian reasoning with each additional year of schooling (Gigerenzer, 2014: pp. 248-253). By natural probabilistic reasoning Gigerenzer means the untutored reasoning people derive from their experience of population samples. Statistical thinking exploits and develops reliance on such intuition (Myers, 2002) about patterns in the natural world: when such intuitions hold up well and, when they do not.

Many schools throughout the world including programs for the International Baccalaureate include instruction in philosophy. Matthew Lipman's lead in teaching elementary school children philosophy continues to expand (Lipman, 2003). Since statistics is a branch of standard philosophy known as inductive logic, making it a part of the fourth " $r$ " by tradition. There is no need to sacrifice any current instruction for something requiring new scaffolding. Rather, there is only a need to feature statistical elements of inductive logic in education in the basic fourth "r" (Gigerenzer, 2014: p. 247). Moreover, since statistical thinking embraces many fundamental tools of probability (albeit in critically astute fa- 
shion), mathematics, an already a well-entrenched K-12 subject, need only align itself each year with further, statistically essential instruction in teaching strategies of mathematical evaluation in conditions of uncertainty.

In upper grades, rather than teach students how to chart data using trigonometry and displacement of data on an $\mathrm{X}$ and $\mathrm{Y}$ axis, math teachers can extend discussion to how charts intentionally or unintentionally represent or misrepresent data even when the math organizing a set of numbers is unimpeachable. The math can be unimpeachable while still susceptible to the vulnerabilities of mismanagement when acquiring and interpreting practices used for accumulating data points (Wagner, 1982). In addition, students need to learn there are statistical tools more applicable to some sets of data but inappropriate for revealing accurate information in another set (Spiegelhalter, 2019).

\section{Summing the Grounds for Responsive Statistical Evaluation across the Curriculum}

Apt instruction for questioning statistical conclusions is essential to life well-lived (Cairo, 2019; Wagner, 2006). For example, deciding whether to undergo expensive or risky additional testing for medical diagnosis or deciding to go on a picnic given the current weather report are unavoidably dependent upon inductive, statistical inferencing. In short, sagacious reflection makes it palpably clear that instruction in statistical evaluation is a true basic. Moreover, as Gigerenzer explains, there are empirical grounds establishing the readiness of students for statistical reasoning from the earliest primary grades onward (Gigerenzer, 2014: pp. 256-261). In short, rather than an addition, instruction in statistics can be taught as a realignment of the current four " $r$ " basic curriculum without and sacrifice of content. The case for instruction in statistics and critical thinking is the heart of the fourth "R". This construction of the fourth " $R$ " should guide curricular theory and practice throughout the K-12 curriculum and beyond. This conviction is unimpeachable given recent empirical research (Pinker, 2021) and theoretical conclusions derived from nearly every sector of STEM studies and scholarship in general (Wagner, 2021). Even in the case of subjects such as character instruction and moral development, the foundational focus on the fourth " $R$ " as an indispensable accompaniment to the success of such instruction has become increasingly transparent to researchers over the past thirty years or more (Wagner, 2007).

\section{Conflicts of Interest}

The author declares no conflicts of interest regarding the publication of this paper.

\section{References}

Cairo, A. (2019). How Charts Lie: Getting Smarter about Visual Information. Norton.

Gigerenzer, G. (2014). Risk Savvy: How to Make Good Decisions. Viking.

Gigerenzer, G., Hertwig, R., \& Pochue, T. (2015). The Foundations of Adaptive Behavior. 
Oxford University Press.

Gottlieb, S. (2021). Why Covid-19 Crushed Us and How We Can Defeat the Next Pandemic. Harper.

Hotez, P. (2021). Preventing the Next Pandemic: Vaccine Diplomacy in a Time of Anti-Science. John Hopkins University Press.

Jackson, P. (2011). What Is Education. University of Chicago Press. https://doi.org/10.7208/chicago/9780226389394.001.0001

Koretz, D. (2008). Measuring Up. What Educational Testing Is Really Tells Us. Harvard University Press. https://doi.org/10.2307/j.ctv1503gxj

Lipman, M. (2003). Thinking in Education (2nd ed.). Cambridge University Press. https://doi.org/10.1017/CBO9780511840272

Myers, D. (2002). Intuitions. Yale University Press.

Pinker, S. (2021). Rationality: What Is It, Why It Seems Scarce, Why It Matters. Viking Press.

Poundstone, W. (2021). How Do You Fight a Horse-Sized Duck? Little, Brown, Spark.

Spiegelhalter, D. (2019). The Art of Statistics: How to Learn from Data. Basic Books. https://doi.org/10.5038/1936-4660.13.1.7

Wagner, P., \& Dede, C. (1983). Disciplinary Paradigm Shifts: A New Frontier for Future Research. World Future Society Bulletin, 17, 25-29.

Wagner, P. (1982). Philosophy in Mathematics Education. Metaphilosophy, 13, 79-90. https://doi.org/10.1111/j.1467-9973.1982.tb00293.x

Wagner, P. A. (2006). Probability, Decision Theory, and a Curricular Approach to Developing Good Thinking. Journal of Thought, 41, 23-38.

Wagner, P. (2007). Moral Self-Assessment Protocol. McGraw-Hill Custom.

Wagner, P. (2021). Refreshing the Teaching of Educational Statistics. Philosophy of Mathematics Journal, $37,8$.

Wagner, P. A., \& Fair, F. (2020). Education for Knowing: Theories of Knowledge for Effective Student-Building. Rowman and Littlefield.

Wagner, P., Johnson, D., Fair, F., \& Fasko, D. (2018). Thinking Ahead: Engaging All Teachers in Critical Thinking. Rowman \& Littlefield.

Wagner, P. A., \& Simpson, D. (2009). Ethical Decision-Making in School Administration. Sage. 